This information is current as of April 26, 2023.

\title{
Proteomic Analysis of Aneurysm Healing Mechanism after Coil Embolization: Comparison of Dense Packing with Loose Packing
}

R. Kadirvel, Y.H. Ding, D. Dai, D.A. Lewis and D.F. Kallmes

AJNR Am J Neuroradiol 2012, 33 (6) 1177-1181

doi: https://doi.org/10.3174/ajnr.A2940

http://www.ajnr.org/content/33/6/1177 


\section{ORIGINAL RESEARCH}

\author{
R. Kadirvel \\ Y.H. Ding \\ D. Dai \\ D.A. Lewis \\ D.F. Kallmes
}

\title{
Proteomic Analysis of Aneurysm Healing Mechanism after Coil Embolization: Comparison of Dense Packing with Loose Packing
}

\begin{abstract}
BACKGROUND AND PURPOSE: In clinical practice, durability of occlusion following coil embolization is superior in densely packed, compared with loosely packed, aneurysms. In a rabbit model, we probed, by using proteomics tools, the biologic mechanisms associated with densely packed and completely occluded aneurysms, compared with loosely packed and incompletely occluded aneurysms, to explore the biologic mechanisms of intra-aneurysmal healing following embolization.
\end{abstract}

\begin{abstract}
MATERIALS AND METHODS: Elastase-induced, saccular aneurysms were created in 24 rabbits. Aneurysms were allowed to mature, after which aneurysms were either densely (packing attenuation $>25 \%$ ) or loosely (packing attenuation $<20 \%$ ) packed with platinum coils by endovascular means. After 2 weeks ( $n=6$ for both groups) and 4 weeks ( $n=6$ for both groups) of implantation, aneurysm samples harboring coils were harvested. Soluble proteins were extracted from the necks and domes of aneurysms, and proteins were studied using proteomics and bioinformatics tools.
\end{abstract}

RESULTS: In dome tissue, 128 proteins at 2 weeks, and 8 proteins at 4 weeks, were differentially expressed in densely packed, compared with loosely packed, aneurysms. In the neck tissue, 2 proteins at 4 weeks were differentially expressed in densely packed aneurysms. Specific pathway analysis revealed that compared with loosely packed aneurysms, densely packed aneurysms were associated with up-regulation of cell-to-cell signaling and cell adhesion at 2 weeks. Conversely, at 4 weeks, densely packed aneurysms showed a decrease in the expression of structural proteins compared with loosely packed aneurysms.

CoNCLUSIONS: These findings may focus efforts on specific targets aimed at improving the long-term healing of intracranial, saccular aneurysms.

ABBREVIATIONS: FDR $=$ false discovery rate; $\mathrm{GO}=$ gene ontology; $\mathrm{KEGG}=$ Kyoto Encyclopedia of Genes and Genomes

C erebral, saccular aneurysms are routinely treated with platinum coils. However, the rate of recanalization after endovascular treatment of aneurysms is high, especially in larger aneurysms. ${ }^{1,2}$ A better understanding of molecular events related to healing or, conversely, to recanalization might lead to interventions designed to prevent aneurysm regrowth or recanalization following endosaccular embolization.

Both clinical and preclinical data have shown that packing attenuation in aneurysms predicts the degree and extent of healing, with loosely packed, wide-neck experimental aneurysms showing features of poor histologic healing, and densely packed, narrow-neck aneurysms demonstrating features of good histologic healing. ${ }^{3,4}$ Clinical findings have also confirmed that angiographic recanalization is related to packing attenuation, with higher rates of recanalization noted with loosely packed aneurysms. ${ }^{5-7}$

Received August 18, 2011; accepted after revision October 12

From the Neuroradiology Research Laboratory, Department of Radiology, Mayo Clinic, Rochester, Minnesota.

This study was supported in part by the funds from National Institutes of Health Grant (2R01NS042646) and American Heart Association Scientist Development grant (AHA 09SDG2160146-01).

Please address correspondence to David F. Kallmes, MD, Professor of Radiology, Mayo Clinic, 200 First St SW, Rochester, MN 55905; e-mail: Kallmes.david@mayo.edu

Indicates open access to non-subscribers at www.ajnr.org

Indicates article with supplemental on-line table.

http://dx.doi.org/10.3174/ajnr.A2940
Our group previously explored the differential gene expression patterns between densely and loosely packed aneurysms using gene microarrays in a rabbit model. ${ }^{8}$ In the current study, we extend our previous work of profiling transcription level analysis to focus on translational level analysis. ${ }^{9}$ Proteins represent the functional end production of gene expression, performing functions essential for most cellular processes. ${ }^{10}$ We probed, by using proteomics ${ }^{1,12}$ and bioinformatics tools, ${ }^{13,14}$ the biologic mechanisms associated with densely packed aneurysms, compared with loosely packed aneurysms, to explore biologic mechanisms of intra-aneurysmal healing following embolization in a rabbit, elastase-induced aneurysm model.

\section{Materials and Methods}

\section{Aneurysm Creation and Embolization}

The Institutional Animal Care and Use Committee (Mayo Clinic, Rochester, Minnesota) approved all procedures before initiation of the study. Aneurysms were created in 24 female New Zealand white rabbits (body weight 3-4 kg) using the elastase-induced aneurysm model in rabbits. ${ }^{15}$ Aneurysms were permitted to mature for 3 weeks after aneurysm creation before embolization. All subjects were embolized with standard platinum coils by endovascular means. ${ }^{16}$

In clinical practice, high packing attenuation is easily achieved in relatively small aneurysms but is difficult or impossible in large aneu- 
rysms. To simulate the clinical environment, we prospectively identified relatively small experimental aneurysms, with maximum aneurysm volume of $50 \mathrm{~mm}^{3}$ or less, to target for "high packing attenuation" experiments, with target volumetric occlusion rates of $>25 \%$ $(41.1 \pm 14.1 \%)$. Conversely, we prospectively identified relatively large aneurysms, with minimum volume of $60 \mathrm{~mm}^{3}$, for "low packing attenuation" experiments, with target volumetric occlusion rates of $<20 \%(13.0 \pm 4.1 \%)$.

The size of the aneurysm cavity was assessed by direct comparison with radiopaque sizing devices during DSA. The volumetric occlusion was calculated in real time, during aneurysm embolization, using the AngiCalc tool (http://www.angiocalc.com/index.aspx). Appropriatesized coils were placed into the aneurysm as in typical practice. After embolization, a final control DSA was performed. The rabbits in each group were randomly assigned to either 2-week $(n=6$ for both groups) or 4 -week ( $n=6$ for each group) survival groups after embolization with platinum coils. These time points were chosen based on predicate data indicating the cellular responses to therapy are metabolically active at earlier time points. ${ }^{17}$

\section{Tissue Harvest}

At the time of euthanasia, animals were deeply anesthetized. DSA was performed, followed by euthanasia using a lethal injection of pentobarbital. The aneurysm sac was horizontally dissected in the middle into 2 parts, including the neck (lower sac) and dome (upper sac). These samples were kept frozen at $-70^{\circ} \mathrm{C}$.

\section{Protein Extraction}

Frozen aneurysm samples were pulverized in liquid nitrogen, and soluble proteins were extracted by homogenizing samples in lysis buffer containing $50 \mathrm{mmol} / \mathrm{L}$ Tris- $\mathrm{HCl}, \mathrm{pH} 7.4,0.1 \%$ sodium dodecyl sulfate, and protease inhibitors. After centrifugation at 10,000 $\mathrm{g}$ for 20 minutes at $4^{\circ} \mathrm{C}$, the protein concentration of the supernatant was determined (Pierce Biotechnology, Rockford, Illinois).

\section{Proteomic Analysis}

One-Dimensional Gel Electrophoresis. Equal amounts of proteins were separated by Criterion XT gels (Bio-Rad Labs, Hercules, California) and stained with BioSafe colloidal blue stain (Bio-Rad Labs). Each lane of the gel was excised from the gel and cut into 5 fractions, based on molecular mass. These gel fractions were subsequently reduced and alkylated, and in gel digestion performed using trypsin. Tryptic peptide extracts were stored frozen at $-80^{\circ} \mathrm{C}$ until analysis by mass spectrometry.

Protein Identification by Mass Spectrometry. The trypsin-generated digests were separated by nanoscale liquid chromatography, coupled with high accuracy mass spectrometry and data-dependent tandem mass spectrometry (nLC-MS/MS), coupled to a nanoLC-2D HPLC system (Eksigent, Dublin, California). Relative protein quantification between the groups was performed on the Orbitrap survey scan data using the Elucidator software package (Rosetta Biosoftware, Seattle, Washington). ${ }^{18,19}$ Peptide sequences were assigned to MS/MS spectra by using the Mascot data base search engine (Ver. 2.2.04, http://www.matrixscience.com). Due to the incomplete representation of rabbit proteins in protein databases, we used a human, mouse, rat, and rabbit subset of the UniProt data base (http://www.uniprot. org), using the homologs from other species as surrogates for the rabbit version of the protein. Validation of the data base search results was done by using the Elucidator implementation of peptide and protein teller algorithms, ${ }^{20,21}$ with an estimated false discovery rate of $1 \%$, esti- mated from reversed sequence protein entries appended to the data base as decoys. ${ }^{22}$ Validated peptides were annotated to their molecular signals across the aligned data from each sample.

\section{Statistical and Bioinformatic Analysis}

Peptide data from 5 gel sections for each comparison results from Elucidator were first combined. Proteins with a statistically significant difference between densely and loosely packed aneurysms $(P<.05$ and FDR $\leq 0.1^{23}$ ), and a fold change $\geq 1.2$ and $\geq 0.8$ to represent upand down-regulation in densely versus loosely packed aneurysms, were used to identify pathways. Redundant proteins from several sections were removed by keeping the one with the lowest $P$ value. Network pathways were reconstructed utilizing the Ingenuity Pathway Analysis tool (http://www.ingenuity.com), and GO and biologic processes were derived by using DAVID Bioinformatics Resources 6.7 (http://david.abcc.ncifcrf.gov). ${ }^{24}$

\section{Results}

\section{Angiographic Findings}

The mean aneurysm volume was statistically smaller in densely packed aneurysms $\left(44.3 \pm 23.5 \mathrm{~mm}^{3}\right)$ compared with loosely packed aneurysms $\left(103.1 \pm 53.7 \mathrm{~mm}^{3}, P=.003\right)$. The volumetric packing attenuation values were higher in densely packed aneurysms $(41.1 \pm 14.1 \%)$ than in the loosely packed aneurysms $\left(13.0 \pm 4.1 \%, P=6.4 \times 10^{-7}\right)$. Representative angiographic images are presented in Fig 1.

\section{Molecular Findings}

In dome tissue, 128 proteins at 2 weeks, and 8 proteins at 4 weeks, were differentially expressed in densely packed, compared with loosely packed, aneurysms. In the neck tissue, 2 proteins at 4 weeks were differentially expressed in densely packed aneurysms. No protein demonstrated statically significant differences between the attenuated packing and loose packing groups at 2 weeks postembolization along the neck.

\section{Proteins Differentially Expressed at 2 Weeks Postembolization}

We performed ontologic enrichment analysis with particular attention to KEGG pathways and GO biologic processes for the proteins that were differentially expressed at the dome of 2 -week aneurysms. This bioinformatics analysis revealed protein up-regulation in the dome of densely packed aneurysms in several broad biologic processes, including proteins involved in energy production, cell adhesion, protein transport, and response to injury (Table 1). Specific up-regulated pathways included the gap junction, citrate cycle, vascular smooth muscle contraction, lysosome, and fatty acid metabolism (Table 2). Our Ingenuity pathway analysis revealed that networks of genetic disorder, metabolic disease, and posttranslational modification were highly up-regulated in the dome of densely packed aneurysms compared with loosely packed aneurysms (Table 3). Proteins exhibiting the highest relative expression in the dome of densely packed compared with loosed packed aneurysms were C-reactive protein (5.7-fold up-regulation) and creatine kinase M-type (3.6-fold).

The expression of plasminogen (0.44-fold), interferoninduced very large GTPase 1 (0.48-fold), and inter-alphatrypsin inhibitor (0.5-fold) were markedly down-regulated in 


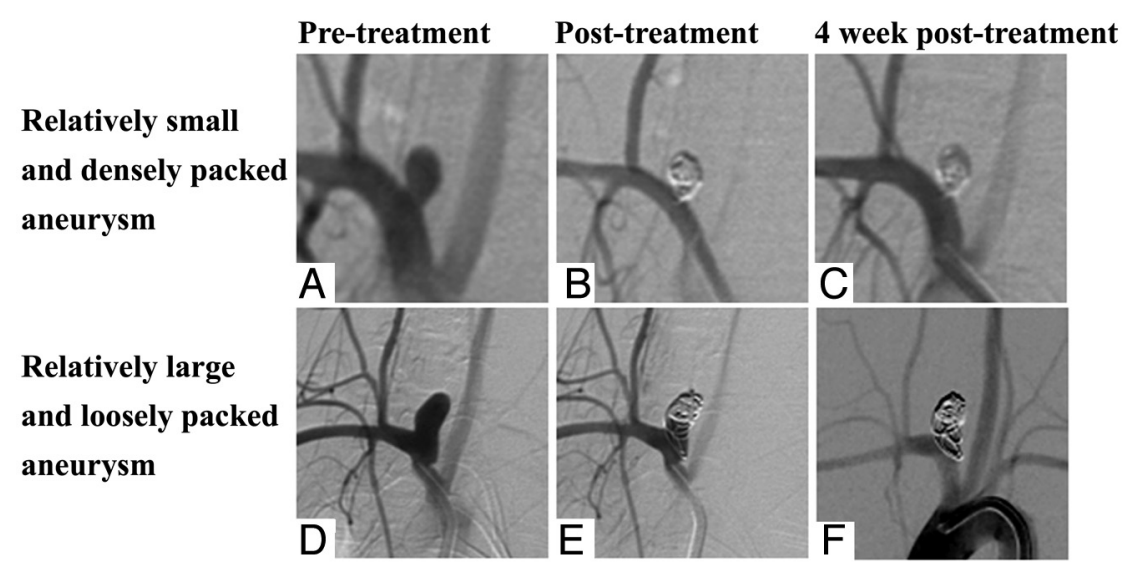

Fig 1. Representative angiograms of densely and loosely packed aneurysms with platinum coils. $A, A$ relatively small aneurysm (volume $<50 \mathrm{~mm}^{3}$ ) cavity before embolization. $B$, The aneurysm was densely packed with platinum coils and the cavity was completely occluded immediately after embolization. $C$, Follow-up image at 4 weeks postembolization shows stable occlusion of the aneurysm from the parental artery. $D$, A relatively large aneurysm (volume $>70 \mathrm{~mm}^{3}$ ) cavity before embolization. $E$, The aneurysm was loosely packed with platinum coils and the cavity did not completely occlude immediately. F, Follow-up image at 4 weeks postembolization shows coil compaction.

\begin{tabular}{|c|c|c|}
\hline Biologic Process & $\begin{array}{l}\text { Number of Proteins } \\
\text { Up-Regulated }\end{array}$ & Protein Symbol \\
\hline Generation of precursor metabolites and energy & 17 & $\begin{array}{l}\text { ALD0A, ALDOC, ATP5A1, ETFA, GNAS, IDH3B, IDH1, MDH2, NDUFA10, PDHA1, } \\
\text { PPP1CA, PYGL, UOCRC2, SUCLG1, SUCLG2, ACAA1, ATP6V1C1 }\end{array}$ \\
\hline Oxidation reduction & 15 & $\begin{array}{l}\text { ACADM, AKR1B10, AKR1C4, CBR1, ETFA, GPD1, IDH3B, IDH1, IVD, KCNAB2, MDH2, } \\
\text { NDUFA10, PDHA1, UOCRC2 }\end{array}$ \\
\hline Response to organic substance & 14 & $\begin{array}{l}\text { GOT2, ALDOC, CA2, CTSC, CORO1A, CRYAB, AHSG, GNAS, IDH1, PRKACA, MAPK1, } \\
\text { PPP2CA, RBM4, THBS1, }\end{array}$ \\
\hline Protein localization & 13 & $\begin{array}{l}\text { GNAS, LMAN2, MAPK1, MVP, MY01C, HSPG2, PPT1, SEC61A1, SELENBP1, SCAMP2, } \\
\text { SNX5, TOMM40, VPS26A }\end{array}$ \\
\hline Response to wounding & 12 & SERPINC1, CRP, VCAN, F13A1, AHSG, FN1, GNA13, GNA0, ITGB2, MGLL, PLG, THBS1 \\
\hline Cell adhesion & 12 & $\begin{array}{l}\text { AEBP1, TGFBI, CORO1A, VCAN, ECM2, FN1, ITGB2, HSPG2, PGM5, RPSA, SPON1, } \\
\text { THBS1 }\end{array}$ \\
\hline Protein transport & 12 & $\begin{array}{l}\text { GNAS, LMAN2, MAPK1, MVP, MY01C, PPT1, SEC61A1, SELENBP1, SCAMP2, SNX5, } \\
\text { TOMM40, VPS26A }\end{array}$ \\
\hline Response to endogenous stimulus & 10 & ALDOC, CA2, CRYAB, AHSG, GNAS, IDH1, PRKACA, MAPK1, RBM4, THBS1 \\
\hline Glucose metabolic process & 9 & ALDOA, ALDOC, CRYAB, GPD1, MDH2, PDHA1, PGM5, PPP1CA, PYGL \\
\hline Response to hormone stimulus & 9 & CA2, CRYAB, AHSG, GNAS, IDH1, PRKACA, MAPK1, RBM4, THBS1 \\
\hline
\end{tabular}

Note:-Top 10 biologic process with descending protein count and Expression Analysis Systematic Explorer (EASE) score, $P<0.05$.

\begin{tabular}{|c|c|c|}
\hline Biologic Pathways & $\begin{array}{c}\text { Number of Proteins } \\
\text { Up-Regulated }\end{array}$ & Protein Symbol \\
\hline Gap junction & 7 & GNAI1, GNAI2, GNAI3, GNA0, GNAS, PRKACA, MAPK1 \\
\hline Citrate cycle & 6 & IDH3B, IDH1, MDH2, PDHA1, SUCLG1, SUCLG2 \\
\hline Vascular smooth muscle contraction & 6 & GNA13, GNAQ, GNAS, PRKACA, MAPK1, PPP1CA \\
\hline Lysosome & 6 & CTSC, CTSD, CTSK, CD63, M6PR, PPT1 \\
\hline Tight junction & 6 & EPB41, ACTG1, GNAI1, GNAI2, GNAI3, PPP2CA \\
\hline Fatty acid metabolism & 5 & ACADL, ACADM, ACAA1, ACAT1, ACAA2 \\
\hline Valine, leucine, and isoleucine degradation & 5 & ACADM, IVD, ACAA1, ACAT1, ACAA2 \\
\hline
\end{tabular}

Note:-Top 10 biologic process with descending protein count and EASE score, $P<0.05$

the dome of densely packed compared with loosely packed aneurysms (On-line Table 1).

\section{Proteins Differentially Expressed at 4 Weeks Postembolization}

Densely packed aneurysm dome tissue, compared with loosely packed dome tissue, demonstrated down-regulation in the expression of structural proteins (cysteine-glycine rich protein-1, transgelin, smooth muscle actin, and actin-alpha 1) and upregulation in the expression of cell signaling proteins (myosine heavy chain-9 and cullin-1) (Table 4).

Compared with loosely packed aneurysms, the neck region of densely packed aneurysms exhibited decreased expression of cytoskeletal adapter protein sorbin and $\mathrm{SH} 3$ domain-containing protein 2 (0.55-fold reduction) and leukotriene prostaglandin reductase-1 (0.53-fold reduction) (Table 5). 


\begin{tabular}{|c|c|c|}
\hline Biologic Process & $\begin{array}{l}\text { Number of Proteins } \\
\text { Up-Regulated }\end{array}$ & Protein Symbol \\
\hline $\begin{array}{l}\text { Genetic disorder, metabolic disease, posttranslational } \\
\text { modification }\end{array}$ & 25 & $\begin{array}{l}\text { ACAA1, ACADL, ACADM, ACAT1, ACTG1, AEBP1, ALDOA, ALDOC, } \\
\text { CAPZA2, CLEC11A, CORO1A, CTSD, ECM2, EMD, ETFA, GNA13, } \\
\text { GNAS, GOT2, IVD, MY01C, PPP1CA, RPSA, TMOD3, TPM2, TWF2 }\end{array}$ \\
\hline $\begin{array}{l}\text { Cell morphology, cellular development, visual system } \\
\text { development and function }\end{array}$ & 21 & $\begin{array}{l}\text { CD63, CRP, CTSK, ELAVL1, F13A1, FN1, GNAI1, GNAI2, GNAI3, } \\
\text { HNRNPA1, HNRNPA2B1, HNRNPUL2, HSPG2, HTRA1, PCBP1, PCOLCE } \\
\text { SLC3A2, TAGLN, TGFBI, TGM2, THBS1 }\end{array}$ \\
\hline $\begin{array}{l}\text { Carbohydrate metabolism, cell cycle, cellular growth } \\
\text { and proliferation }\end{array}$ & 16 & $\begin{array}{l}\text { ACAA2, ACY1, BUB3, CAB39, EHD3, PPT1, PYGL, RBM4, SNX5, } \\
\text { STOML2, SUCLG1, SUCLG2, SULT1A1, TTC35, TUFM, VPS26A }\end{array}$ \\
\hline $\begin{array}{l}\text { Energy production, small molecule biochemistry, cell } \\
\text { morphology }\end{array}$ & 14 & $\begin{array}{l}\text { ALD0A, ATP5A1, DNAJB11, EIF3H, FMNL1, MDH2, OGN, PRKCDBP, } \\
\text { SCAMP2, SELENBP1, SFXN3, SLC3A2, TCEA1, TGFBI }\end{array}$ \\
\hline $\begin{array}{l}\text { Carbohydrate metabolism, small molecule biochemistry, } \\
\text { cell-to-cell signaling and interaction }\end{array}$ & 14 & $\begin{array}{l}\text { AEBP1, AKR1B10, CKM, CLEC3B, ERLIN2, HLA-A, IDH1, IDH3B, KCNAB2, } \\
\text { LMAN2, MGLL, MOBKL1A, PLD3, SERPINB1 }\end{array}$ \\
\hline
\end{tabular}

\begin{tabular}{|c|c|c|c|c|c|c|}
\hline Protein Symbol & Protein Name & $\begin{array}{c}\text { UniProt } \\
\text { Accession ID }\end{array}$ & $\begin{array}{l}\text { Fold } \\
\text { Change }\end{array}$ & $P$ Value & $\begin{array}{c}\text { FDR } \\
(q \text { Value })\end{array}$ & $\begin{array}{c}\text { Protein } \\
\text { Classification }\end{array}$ \\
\hline CSRP1 & Cysteine and glycine-rich protein-1 & P21291 & 0.27 & 1.07E-05 & 0.007 & Other \\
\hline HSPA1A/HSPA1B & Heat shock 70kDa protein-1A & 061696 & 0.38 & 1.15E-04 & 0.028 & Other \\
\hline TAGLN & Transgelin & 001995 & 0.39 & 1.00E-03 & 0.1 & Other \\
\hline ACTA2 & Actin, alpha 2, smooth muscle, aorta & P62736 & 0.46 & 7.77E-05 & 0.024 & Other \\
\hline ACTC1 & Actin, alpha, cardiac muscle 1 & P68032 & 0.57 & 3.40E-05 & 0.014 & Enzyme \\
\hline EIF3A & $\begin{array}{l}\text { Eukaryotic translation initiation factor } 3 \text {, } \\
\text { subunit A }\end{array}$ & 014152 & 1.46 & 4.95E-04 & 0.067 & Translation regulator \\
\hline CUL1 & Cullin-1 & 013616 & 1.6 & 0.001 & 0.1 & Cell cycle regulator \\
\hline MYH9 & Myosin, heavy chain 9, nonmuscle & P35579 & 1.9 & 2.46E-04 & 0.038 & Enzyme \\
\hline
\end{tabular}

Table 5: Proteins that are differentially expressed in the neck of densely packed aneurysms compared with loosely packed aneurysms at 4 weeks following coil embolization

\begin{tabular}{llccccc}
\hline $\begin{array}{l}\text { Protein } \\
\text { Symbol }\end{array}$ & \multicolumn{1}{c}{ Protein Name } & $\begin{array}{c}\text { UniProt } \\
\text { Accession ID }\end{array}$ & $\begin{array}{c}\text { Fold } \\
\text { Change }\end{array}$ & $P$ Value & $\begin{array}{c}\text { FDR } \\
(q \text { Value) }\end{array}$ & $\begin{array}{c}\text { Protein } \\
\text { Classification }\end{array}$ \\
\hline PTGR1 & Prostaglandin reductase 1 & 014914 & 0.53 & $1.50 \mathrm{E}-05$ & 0.010 & Enzyme \\
SORBS2 & Sorbin and SH3 domain containing 2 & 094875 & 0.55 & $1.69 \mathrm{E}-04$ & 0.082 & 0 Other \\
\hline
\end{tabular}

\section{Discussion}

Our group has previously studied the role of a limited number of genes by using transcription-level analysis to probe the healing mechanism in aneurysms treated with platinum coils. ${ }^{8}$ In the present study, we have extended our previous work through the use of proteomic analysis, which not only provides a substantially greater number of genes and pathways that can be studied but also focuses on the translational, rather than transcriptional, level processes as seen with gene chips.

In the current study, we identified several biologic pathways differentially expressed between groups in distinct areas of the aneurysm cavity. Early after aneurysm embolization, the dome of densely packed aneurysms showed increased expression of cell-signaling molecules, cell-adhesion molecules, and acute-phase proteins compared with loosely packed aneurysms. However, we later noted decreased expression of cytoskeleton molecules in densely packed compared with loosely packed aneurysms. This constellation of findings suggest that modifications aimed at improved long-term outcomes likely need to act at early time points following implantation and logically would target adhesion molecules and related acutephase proteins.

The most markedly up-regulated protein was C-reactive protein in the dome of densely packed aneurysms at 2 weeks. C-reactive protein is an acute-phase protein and is a marker of inflammation. ${ }^{25}$ Its level increases in blood in response to tissue injury. ${ }^{26,27}$ This observation may lend credence to the "inflammatory" hypothesis put forth by numerous investigators who have proposed the use of bioactive materials to improve aneurysm healing. Importantly, the expression of proteins associated with cell adhesion and wound-healing mechanisms (fibronectin, thrombospondin, and versican) were elevated in the dome of densely packed aneurysms at 2 weeks. Fibronectin plays a crucial role in wound healing, as it is deposited at the site of injury, where it binds with fibroblasts and induces the differentiation of fibroblast, thereby promoting wound repair. ${ }^{28}$ In the current study, we noted that the increase in the energy production mechanism was highly active, as evidenced by the elevation in proteins participating in the carbohydrate and fatty acid metabolic pathways of densely packed aneurysms. 
Our data further demonstrated that the expression of cysteine and glycine-rich protein-1 is dramatically increased in the dome of loosely packed aneurysms at 4 weeks after coil embolization. Cysteine and glycine-rich protein-1 is involved in regulatory processes important for development and cellular differentiation, particularly in actin-cytoskeleton organization. ${ }^{29}$ Increased expression of this protein in loosely packed aneurysms suggests ongoing cell differentiation in the loosely packed aneurysm with platinum coils.

Increased levels of cell adhesion molecules and decreased levels of structural molecules in the dome of densely packed aneurysms, compared with loosely packed aneurysms, at 2 weeks are in accordance with our previous study, ${ }^{8}$ which focused on gene expression profiling between densely and loosely packed aneurysms. However, in the current study, we observed that only 2 proteins (sorbin and SH3 domain-containing protein 2 and leukotriene prostaglandin reductase-1) are differentially expressed at the neck of 4-week densely packed aneurysms, compared with 25 genes noted in our previous gene expression study. ${ }^{8}$ The difference in the expression of number of proteins or genes may be attributed to a mass spectrometry analysis limitation, which is more sensitive in analyzing the highly abundant peptide fragments that mask the less abundant peptides. In addition, not all messenger RNA transcripts are necessarily translated into proteins.

The present study suffers some limitations. Neither densely nor loosely packed aneurysms were compared with untreated aneurysms. Cell-specific protein expression analysis would offer additional information in understanding the mechanism of healing or recurrence of treated aneurysms. Because the availability of the rabbit-specific protein data base is limited, we retrieved protein data from available animal and human data bases. We did not perform detailed pathway analysis for 4-week aneurysms, as the number of differentially expressed proteins was low. We acknowledge that this was an exploratory and preliminary study with only 2 time points.

\section{Conclusions}

In the rabbit saccular aneurysm model, increased protein expression in the densely packed aneurysms was associated with cell-signaling molecules. Loosely packed aneurysms showed an elevated expression of structural molecules.

\section{Acknowledgments}

We express our gratitude to Dr. Robert Bergen III, Mr. Kenneth Johnson, and Ms. Cristine Charlesworth, Mayo Proteomics Research Center, and Dr. Zhifu Sun, Department of Biomedical Statistics and Informatics, Mayo Clinic, Rochester, Minnesota, for their generous help with the study.

Disclosures: Debra Lewis-RELATED: Grant: NINDS NS042646, Comments: Grant title: "Improved Animal Modeling of Saccular Aneurysms"; part of the results from Specific Aim III. David Kallmes—RELATED: Grant: NIH; UNRELATED: Grants/Grants Pending: eV3, Penumbra, Micrus, MicroVention, Sequent, NFocus; Payment for Development of Educational Presentations: eV3, CareFusion; Travel/Accomodations/Meeting Expenses Unrelated to Activities Listed: MicroVention.

\section{References}

1. Gallas S, Januel AC, Pasco A, et al. Long-term follow-up of 1036 cerebral aneurysms treated by bare coils: a multicentric cohort treated between 1998 and 2003. AJNR Am J Neuroradiol 2009;30:1986-92
2. Whitlow CT, Geer CP, Mattern CW, et al. Endovascular histologic effects of ultrathin gold- or vitronectin-coated platinum aneurysm coils in a rodent arterial occlusion model: a preliminary investigation. AJNR Am J Neuroradiol 2009;30:85-90

3. Ding YH, Dai D, Kadirvel R, et al. Relationship between aneurysm volume and histologic healing after coil embolization in elastase-induced aneurysms: a retrospective study. AJNR Am J Neuroradiol 2008;29:98-101

4. Sluzewski M, van Rooij WJ, Slob MJ, et al. Relation between aneurysm volume, packing, and compaction in 145 cerebral aneurysms treated with coils. Radiology 2004;231:653-58

5. Wakhloo AK, Gounis MJ, Sandhu JS, et al. Complex-shaped platinum coils for brain aneurysms: higher packing density, improved biomechanical stability, and midterm angiographic outcome. AJNR Am J Neuroradiol 2007;28: 1395-400

6. Kawanabe Y, Sadato A, Taki W, et al. Endovascular occlusion of intracranial aneurysms with Guglielmi detachable coils: correlation between coil packing density and coil compaction. Acta Neurochir (Wien) 2001;143:451-55

7. Gaba RC, Ansari SA, Roy SS, et al. Embolization of intracranial aneurysms with hydrogel-coated coils versus inert platinum coils: effects on packing density, coil length and quantity, procedure performance, cost, length of hospital stay, and durability of therapy. Stroke 2006;37:1443-50

8. Kadirvel R, Ding YH, Dai D, et al. Differential gene expression in well-healed and poorly healed experimental aneurysms after coil treatment. Radiology 2010;257:418-26

9. Roepstorff $\mathrm{P}$. Mass spectrometry in protein studies from genome to function. Curr Opin Biotechnol 1997;8:6-13

10. Lodish H BA, Kaiser CA, Krieger M, et al. Molecular Cell Biology (6th ed). New York: W.H. Freeman and Company; 2008

11. Aebersold R, Mann M. Mass spectrometry-based proteomics. Nature 2003;422:198-207

12. Domon B, Aebersold R. Mass spectrometry and protein analysis. Science 2006;312:212-17

13. Huang da W, Sherman BT, Lempicki RA. Bioinformatics enrichment tools: paths toward the comprehensive functional analysis of large gene lists. Nucleic Acids Res 2009;37:1-13

14. Sherman BT, Huang da W, Tan Q, et al. DAVID Knowledgebase: a gene-centered database integrating heterogeneous gene annotation resources to facilitate high-throughput gene functional analysis. BMC Bioinformatics 2007; 8:426

15. Altes TA, Cloft HJ, Short JG, et al. 1999 ARRS Executive Council Award. Creation of saccular aneurysms in the rabbit: a model suitable for testing endovascular devices. American Roentgen Ray Society. AJR Am J Roentgenol 2000;174:349-54

16. Kallmes DF, Helm GA, Hudson SB, et al. Histologic evaluation of platinum coil embolization in an aneurysm model in rabbits. Radiology 1999;213:217-22

17. Kadirvel R, Ding YH, Dai D, et al. Molecular indices of apoptosis activation in elastase-induced aneurysms after embolization with platinum coils. Stroke 2007;38:2787-94

18. Neubert H, Bonnert TP, Rumpel K, et al. Label-free detection of differential protein expression by LC/MALDI mass spectrometry. J Proteome Res 2008; 7:2270-79

19. Wiener MC, Sachs JR, Deyanova EG, et al. Differential mass spectrometry: a label-free LC-MS method for finding significant differences in complex peptide and protein mixtures. Anal Chem 2004;76:6085-96

20. Keller A, Nesvizhskii AI, Kolker E, et al. Empirical statistical model to estimate the accuracy of peptide identifications made by MS/MS and database search. Anal Chem 2002;74:5383-92

21. Nesvizhskii AI, Keller A, Kolker E, et al. A statistical model for identifying proteins by tandem mass spectrometry. Anal Chem 2003;75:4646-58

22. Elias JE, Gygi SP. Target-decoy search strategy for increased confidence in large-scale protein identifications by mass spectrometry. Nat Methods 2007;4:207-14

23. Benjamini $Y$, Hochberg $Y$. Controlling the false discovery rate: a practical and powerful approach to multiple testing. J Royal Stat Soc B 1995;57:289-300

24. Huang da W, Sherman BT, Lempicki RA. Systematic and integrative analysis of large gene lists using DAVID bioinformatics resources. Nat Protoc 2009; 4:44-57

25. Pepys MB, Hirschfield GM. C-reactive protein: a critical update. J Clin Invest 2003;111:1805-12

26. Pritchett JW. C-reactive protein levels determine the severity of soft-tissue injuries. Am J Orthop (Belle Mead NJ) 1996;25:759-61

27. Griselli M, Herbert J, Hutchinson WL, et al. C-reactive protein and complement are important mediators of tissue damage in acute myocardial infarction. J Exp Med 1999;190:1733-40

28. Kohan M, Muro AF, White ES, et al. EDA-containing cellular fibronectin induces fibroblast differentiation through binding to alpha4beta7 integrin receptor and MAPK/Erk 1/2-dependent signaling. FASEB J 2010;24:4503-12

29. Kihara T, Shinohara S, Fujikawa R, et al. Regulation of cysteine-rich protein 2 localization by the development of actin fibers during smooth muscle cell differentiation. Biochem Biophys Res Commun 2011;411:96-101 